\title{
Proceeding
}

9th INSHS International Christmas Sport Scientific Conference, 4-6 December 2014. International Network of Sport and Health Science. Szombathely, Hungary

\section{Soccer players training load during Estonian Premium League matches: comparison of high and low ranking teams}

\author{
MIKOLA MISJUK ${ }^{1}$, NORBERT HURT ${ }^{2}$, INDREK RANNAM ${ }^{1}$ \\ ${ }^{1}$ Institute of Health Sciences and Sports, Tallinn University \\ 2 Football Club Flora
}

\begin{abstract}
Misjuk, M., Hurt, N., \& Rannam, I. (2015). Soccer players training load during Estonian Premium League matches: comparison of high and low ranking teams. J. Hum. Sport Exerc., 9(Proc1), pp.S521-S525. This paper compares training load of a high ranking soccer team with a low ranking team. Two Estonian Premium League soccer teams participated in this study. One team was ranked in the top and the ohter ranked in the bottom of Estonian Premium League Championships. Both teams played against a team ranking in the middle of Estonian Premium League Championships. Study consists of 21 field players: 11 players from the high ranking team $(22,3 \pm 4,2 \mathrm{yrs} ; 181,0 \pm 6,9 \mathrm{~cm} ; 74,9 \pm 8,1 \mathrm{~kg})$ and 10 players from the low ranking team $(22,0 \pm 4,4 \mathrm{yrs} ; 183,1 \pm 4,7 \mathrm{~cm} ; 78,2 \pm 5,5 \mathrm{~kg})$. Match performance data was measured by BioHarness 3 monitors and OmniSense software (Zephyr Technology Corporation). Statistically significant difference between the high and the low ranking team is found for: mechanical intensity, mechanical load, training intensity and training load. No statistically significant difference between the high and the low ranking team is found for: physiological intensity and physiological load. Higher ranking team has lower training load than lower ranking team during a soccer match. This result indicates that it is necessary to improve technical and tactical skills to reduce training load during a soccer matches. Lower training load ensures the stability of tactical and technical skills during the match. Key words: SOCCER, TRAINING LOAD, MATCH PERFORMANCE.
\end{abstract}

\footnotetext{
Corresponding author. Institute of Health Sciences and Sports, Tallinn University, Räägu 49, 11311 Tallinn, Estonia. E-mail: Mikola.Misjuk@tlu.ee 9th INSHS International Christmas Sport Scientific Conference, 4-6 December 2014. International Network of Sport and Health Science. Szombathely, Hungary. JOURNAL OF HUMAN SPORT \& EXERCISE ISSN 1988-5202

(c) Faculty of Education. University of Alicante doi:10.14198/jhse.2015.10.Proc1.47
} 


\section{INTRODUCTION}

Training load in soccer can be described as external (distance covered) and internal (heart rate parameters; PRE) (Impellizzeri et al., 2005; Scott et al., 2013; Abukat et al., 2014). Internal training load requires quantification of the physiological stress experienced by athletes. It may therefore be viewed as an athletes response to an external training load (Impellizzeri et al., 2005). During a competitive match, soccer field players at elite level run between 10 and $13 \mathrm{~km}$ and the mean exercise intensity is $80-90 \%$ of maximum heart rate and the heart rate range is $65-98 \%$ (Helgerud et al., 2001; Alexandre et al., 2012, Bangso et al., 2006; Coelho et al., 2011). Estimated energy expenditure is 1200-1500 kcal (Osgnach et al., 2009). Energy expenditure varies with training conditions pitch size, number of players, players position and opponent team (Reilly, 1997; Rampinini et al, 2007; Coutss et al., 2008; Aslan, 2013). Players spend approximately $50 \%$ of playing time in intensity over $85 \%$ of maximum heart rate zone (Sagarra, 2008; Coelho et al., 2011), while most of the playing time in soccer match is spent in $70-85 \%$ of maximum heart rate zone (Coelho et al., 2011). The identification of physiological loads play important role by soccer training or match play (Alexandre et al., 2012). While the duration of the training session is simple to measure, exercise intensity is more difficult to quantify in soccer (Alexiu \& Couts 2008).

The scientific literature provides a large number of studies on the energetics and biomechanics of constant speed running, but there are much less studies on variable movement activities like soccer (Osgnach et al., 2009). The most common methods to quantify training intensity and training load in field sports are heart rate and ratings of perceived exertion (Impellizzeri et al., 2005; Alexiou \& Coutts 2008; Coutts et al., 2008; Abukat et al., 2014, Foster et al., 2001). Internal training load affects ultimately training outcome, meaning that distance-based measurements are unlikely to show any dose-response relationship, and do date there is no literature to suggest this in soccer or intermittent team sports (Akubat, 2014).

Soccer is a sport where two opposing teams interact to gain superiority over each other (McGarry et al., 2002). Players cover more total distance and high intensity running when playing against higher ranking opponents compared to playing against lower ranking opponents (Castellano et al., 2011; Di Salvo et al., 2009). In addition, previous studies have found that teams with high percentage of ball possession covered less total distance and high speed running than teams with low percentage of ball possession (Bradley et al., 2013). Most of successful teams covered less total distance, less high intensity running and less very high intensity running compared to the less successful teams (Rampinini et al., 2007). Amount of training load is important because it affects physical ability. Physical ability of a player ensures stability of the tactical and technical skills throughout a match (Njororai, 2012).

\section{METHODS}

Two Estonian Premier League soccer teams participated in this study. One team was in the top and the other team was in the bottom of the Estonian Premier League Championships. Both teams played against a team that was in the middle of the Estonian Premier League Championships. The number of participants was: 21 field players, 11 players in the higher ranking team $(22.3 \pm 4.2 \mathrm{yrs}, 181 \pm 6.9 \mathrm{~cm}, 74.9 \pm 8.1 \mathrm{~kg})$ and 10 players in the lower ranking team $(22.0 \pm 4.4 \mathrm{yrs}, 183.1 \pm 4.7 \mathrm{~cm}, 78.2 \pm 5.5 \mathrm{~kg})$. There was a 20 min warm up programme before the games, which consisted of running exercises, ball holding exercises, "shadow game", strikes and speed exercises. Match performance data was measured by BioHarness 3 monitors and OmniSense software (Zephyr Technology Corporation). All measurements took place during the game and was monitored in real-time. Both games took place in the home stadium. Weather conditions were between $8^{\circ} \mathrm{C}$ and $13^{\circ} \mathrm{C}$. 
The following indicators were measured:

- $\quad$ Heart rate parameters: maximum heart rate (max HR), average heart rate (avg HR), percentage of maximum heart rate $(\% \mathrm{HR}$ max $)$

- $\quad$ Energy expenditure (kcal/per min)

- $\quad$ Time in 3 zones: \% time $>85 \%$ max HR, \% time $65-84 \% \max \mathrm{HR}$, time < $65 \% \max \mathrm{HR}$

- Mechanical intensity is based on absolute acceleration, value scaled 1-10 (0-3g)

- Mechanical load is measured as the accumulation of the mechanical intensity value per/min

- $\quad$ Physiological intensity is measured as a heart rate-based index, value scaled 1-10

- $\quad$ Physiological load is measured as the accumulation of the physiological intensity per/min

- $\quad$ Training intensity = AVG physiological intensity + AVG mechanical intensity

- $\quad$ Training load $=$ AVG physiological load + AVG mechanical load

Descriptive statistics was expressed as mean \pm standard deviation (SD) (table 1). Results were statistically analysed using t-test to estimate statistically significant differences between high and low ranking team.

\section{RESULTS}

Results are presented in table 1. Statistically significant difference between the high and the low ranking team is found for the following indicators: mechanical intensity, mechanical load, training intensity and training load. Higher ranking team has lower training load than lower ranking team during a soccer match. No statistically significant difference between the high and the low ranking team is found for the following indicators: physiological intensity and physiological load. Additionally no statistically significant difference between the high and the low ranking team is found for: max HR, avg HR, \% max HR, time spent in different zones, and energy expenditure.

Table 1. Physical activity parameters during the match.

\begin{tabular}{|c|c|c|c|c|c|c|c|c|c|c|c|c|c|c|}
\hline 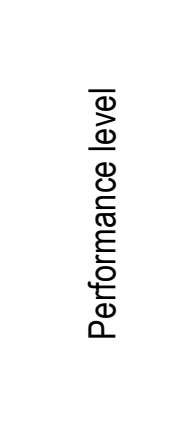 & 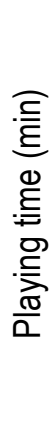 & 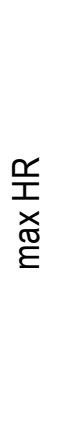 & 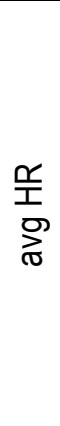 & $\begin{array}{l}\frac{1}{1} \\
\frac{x}{\sigma} \\
\frac{\mathbb{E}}{0} \\
\frac{0}{0}\end{array}$ & 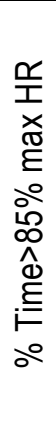 & 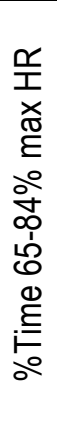 & 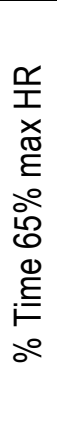 & 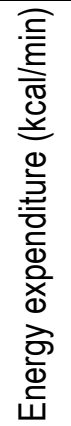 & 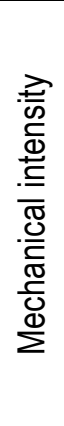 & 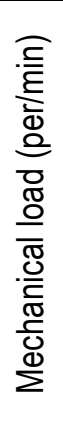 & 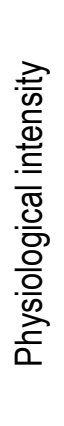 & 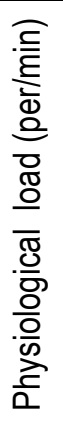 & 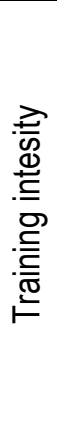 & 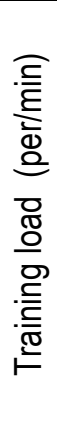 \\
\hline $\begin{array}{l}\text { High ranking } \\
(n=11)\end{array}$ & $\begin{array}{l}\infty \\
\infty \\
\infty+1 \\
10 \\
\infty \\
\infty\end{array}$ & $\begin{array}{l}0 \\
0 \\
+1 \\
10 \\
0 \\
0 \\
0\end{array}$ & $\begin{array}{l}\infty \\
\infty \\
1 \\
+1 \\
0 \\
0 \\
\dot{0}\end{array}$ & $\begin{array}{l}+ \\
\infty \\
+1 \\
⿱ \\
⿱ 亠 䒑 \\
N\end{array}$ & $\begin{array}{l}\stackrel{\infty}{\sim} \\
\stackrel{+1}{+1} \\
\infty \\
\dot{y}\end{array}$ & 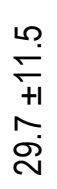 & \begin{tabular}{l}
$m$ \\
$\infty$ \\
$\stackrel{+}{+1}$ \\
\multirow{2}{*}{} \\
$\stackrel{N}{N}$
\end{tabular} & $\begin{array}{l}\stackrel{0}{\sim} \\
+1 \\
\stackrel{+}{\dddot{m}}\end{array}$ & $\begin{array}{l}\infty \\
0 \\
+1 \\
+ \\
0 \\
10\end{array}$ & $\begin{array}{l}\infty \\
0 \\
+1 \\
m \\
m\end{array}$ & $\begin{array}{l}+ \\
0 \\
+1 \\
0 \\
\dot{0}\end{array}$ & $\begin{array}{l}\stackrel{m}{-} \\
+1 \\
\sim \\
\sim\end{array}$ & $\begin{array}{l}m \\
0 \\
+1 \\
+ \\
\dot{0}\end{array}$ & $\begin{array}{l}\check{F} \\
+1 \\
m \\
\dot{\sigma}\end{array}$ \\
\hline Low ranking & 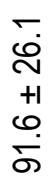 & 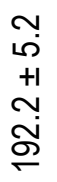 & 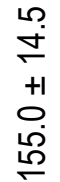 & $\begin{array}{l}0 \\
0 \\
+1 \\
0 \\
0 \\
\infty\end{array}$ & 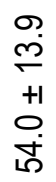 & $\begin{array}{l}5 \\
\infty \\
+1 \\
\dddot{v} \\
\infty\end{array}$ & $\begin{array}{l}\check{m} \\
\stackrel{5}{+1} \\
\infty \\
\stackrel{1}{\sigma}\end{array}$ & $\begin{array}{l}\infty \\
\sim \\
+1 \\
6 \\
\dot{v}\end{array}$ & $\begin{array}{l}0 \\
0 \\
+1 \\
\infty \\
\infty \\
0\end{array}$ & $\begin{array}{l}\hat{O} \\
+ \\
+1 \\
\infty \\
\dot{\gamma}\end{array}$ & $\begin{array}{l}\check{r} \\
+1 \\
0 \\
0\end{array}$ & $\frac{m}{+1}$ & $\begin{array}{l}0 \\
0 \\
+1 \\
\frac{1}{0}\end{array}$ & $\begin{array}{l}\infty \\
0 \\
+1 \\
+ \\
\dot{0}\end{array}$ \\
\hline $\begin{array}{l}\text { t-test } \\
\text { (p-value) }\end{array}$ & & 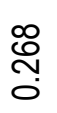 & ָָ & $\frac{\hat{m}}{\stackrel{0}{\circ}}$ & 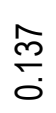 & $\frac{\stackrel{R}{+}}{\stackrel{0}{0}}$ & 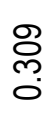 & $\begin{array}{l}\text { \& } \\
\text { N̦ } \\
0\end{array}$ & $\stackrel{N}{\circ}$ & চ্. & $\frac{\text { O্ }}{\stackrel{0}{\circ}}$ & $\frac{\tilde{D}}{\tilde{0}}$ & 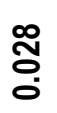 & $\frac{\infty}{\delta}$ \\
\hline
\end{tabular}




\section{DISCUSSION}

Results of current study are in line with the previous study where players spent approximately $50 \%$ of playing time in intensity over $85 \%$ of maximum heart rate zone (Sagarra, 2008; Coelho et al., 2011). Average heart rate during the game was in current study lower than in the previous studies, also percentage of maximum heart rate was lower in the high ranking team than in the previous study, but not in the lower ranking team (Sagarra, 2008; Alexandre et al., 2012). Energy expenditure amount of the current study is well in line with the previous study (Bangsbo, 1994, Osgnach et al., 2009). All observed indicators have tendency to indicate lower stress level in high ranking team compared low ranking team. Results of current study are in line with previous studies where players cover more total distance and high intensity running when playing against higher ranking opponents compared to playing against lower ranking opponents (Rampinini et al., 2007; Di Salvo et al., 2009; Castellano et al., 2011). Greater distance of high intensity running increases mechanical load and physiological load and thereby also training load. Moving backwards or sideways, frequent alternations of activities, numerous accelerations and decelerations, change of direction and unusual movement patterns contribute to the energy expenditure (Reilly, 1997). These kinds of activities are more common to the defensive team than to the dominating team. Playing against stronger opponent induces more synchronised activity and more collaborative work in the attack and the defense phase (Duarte et al., 2012).

Lower stress response to training load may refer also that high raking team players had better physical abilities that lower ranking team players. High raking team players response to physical stimulus was lower during the match. High raking team was professional in this study, but low raking team was amateur soccer team. Top-level soccer players should be physically prepared so that they can cover greater total distance and slightly further at higher intensities when competing against higher quality opponents (Rampinini et al. 2007). It is suggested to play against stronger opponents during the pre-season preparation, this promotes more synchronized activity and induces greater physical activity by players. Playing against stronger opponents induces better tactical and physical development. (Folgado et al., 2014).

\section{CONCLUSIONS}

Higher ranking team has lower training load than lower ranking team during a soccer match. This result indicates that it is necessary to improve technical and tactical skills to reduce training load during soccer matches. Lower training load ensures the stability of tactical and technical skills during the match.

\section{REFERENCES}

1. Abukat, I., Barret, S., \& Abt, G. (2014). Intergrating the Internal and External Training Loads in Soccer. Int J Sports Physiol Perfom. 9, pp.457-462.

2. Alexandre, D., Da Silva, Cd., Hill-Haas, S., Wong, D., Natali, A., De Lima, J., Filho, M., Marins, J., Garcia, E., \& Karim, C. (2012). J Strength Cond Res. 26, pp 2890-2906.

3. Alexiou, H., \& Coutts, A. (2008). A Comparison of Methods Used for Quantifying Internal Training Load in Women Soccer Players. Int J Sports Physiol Perform. 3, pp.1-12.

4. Aslan, A. (2013).Cardiovascular Responses, Perceived Exertion and Technical Actions During Small-Sided Recreational Soccer: Effects of Pitch Size and Number of Players. J Hum Kin.38, pp.95-105.

5. Bangsbo (1994) Energy demands in competitive soccer. J Sports Sci. 12, pp.5-12. 
6. Bangsbo, J., Mohr, M., \& Krustrup, P. (2006) Physical and metabolic demands of training and match-play in the elite football player. J Sports Sci. 24, pp,665-674

7. Bradley, P., Lago-Penas, R.E., \& Diaz, A. (2013) The effect of high and low percentage ball possession on physical and technical profilies in English FA Premier League soccer matches. $J$ Sports Sci. 31, pp.1261-1270.

8. Castellano, J., Blanco-Villasenor, A., \& Alvarez, D. (2011). Contextual Variables and Time-Motion Analysis in Soccer. Int J Sports Med. 32, pp.415-421.

9. Coelho, D., Mortimer, L., Condessa, L., Morandi, R., Oliveira B., Marins, J., Soares, D., \& Garcia, E. (2011). Intensity of real competitive soccer matches and differences among player positions. Rev Bras Cineantropom Desempenho Hum. 13, pp.341-347.

10. Coutss, A., Rampinini, E., Marcora, S., Castagna, C., \& Impellizeri, F.(2008). Heart rate and blood lactate correlates of perceived exertion during small-sided soccer games. J Sci Med Sports. 12, pp.79-84.

11. Di Salvo, V., Gregson, W., Atkinson, G., Tordoff, P., \& Drust, B. (2009). Analysis of High Intensity in Premier League Soccer. Int J Sports Med. 30, pp.205-2012.

12. Duarte, R., Araujo, D., Correia, V., \& Davids, K. (2012) Sports teams as superorganisms: implications of sociobiological models of behaviour for research and practice in team sports performance analysis. Sports Med 42, pp.633-642.

13. Folgado, H., Duarte, R., Fernandes, O., \& Sampaio, J. (2014). Competing with Lower Level Opponents Decreases Intra-Team Movement Synchronization and Time-Motion Demands during Pre-Season Soccer Matches. Plos One. 9(5).

14. Foster, C., Florhaug, J., Franklin, J., Gottschall, L., Hrovation, L, Parker, S., Doleshal, P., \& Lodge, C. (2001). A New Approach to Monitoring Exercise Training. J Strength Cond Res.15, pp.109-115.

15. Helgerud, J., Engen, L., Wisloff, U., \& Hoff, J. (2001). Aerobic endurance training improves soccer performance. Med Sci Sports Exerc. 33, pp.1925-1931.

16. Impellizzeri, F., Rampinini, E., \& Marcora, S. (2005). Physiological assessment of aerobic training in soccer. J Sports Sci. 23, pp.583-592.

17. Mcgarry, T., Anderson, D., Wallace, S., Hughes, M., \& Franks, I. (2002) Sport competition as a dynamical self-organizing system. J Sport Sci. 20, pp.771-781.

18. Njororai, W. (2012). Physical Demands of Soccer: Lessons from Team USA and Ghana Matches in the 2010 FIFA WORLD CUP. J Phys Educ Sport. 12, pp.407-412.

19. Osgnach, C., Poser, S., Bernardini, R., Rinaldo, R., \& Di Prampero, P. (2009) Energy Cost and Metabolic Power in Elite Soccer: A New Match Analysis Approach. Med Seci Sports Exerc. 42, pp.170-179.

20. Rampinini, E., Coutss, A., Castagna, C., Sassi, R. \& Impellizeri, F. (2007).Variatation in Top Level Soccer Match Performance. Int J Sports Med. 28, pp. 1018-1024.

21. REILLY T. (1997). Energetics of high-intensity exercise (soccer) with particular reference to fatigue. J Sports Sci. 15, pp.257-263.

22. Sagarra, M. (2008). Demonstration of mechanical and physiological variables in professional football matches.

[http://gpsports.com/gpsports_website/research/Lapuente\%20Demonstration\%20of\%20mechanical \%20and\%20physiological\%20variables\%20in\%20professional\%20footballmatches.pdf]

23. Scott, B., Lockie, R., Knigth, T., Clark, A., \& De Jonge X. (2013). A Comparison of Methods to Quantify the In-Season Training Load of Professional Soccer Players. Int J Sports Physiol Perform. 8, pp.195-202. 